\title{
Die Romeins-Hollandse Reg na 300 Jaar Gehandhaaf en Versterk.
}

„Driemaal het Rome aan die wêreld wette gedikteer, driemaal die volkere tot eenheid verbind"-met hierdie woorde begin een van die beroemdste juriste van die 19 de eeu sy ewe beroemde werk oor „Die gees

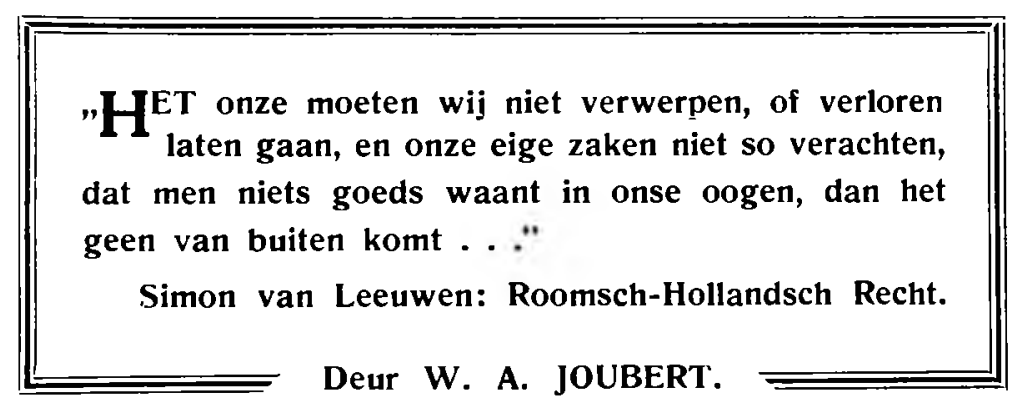

van die Romeinse reg"-, ,die eerste keer, toe die Romeinse volk nog in die volheid van sy krag gestaan het, tot eenheid van staat, die tweede keer, toe hy reeds ondergegaan was, tot eenheid van kerk, die derde keer, as gevolg van die resepsie van die Romeinse reg in die Middeleeue, tot eenheid van reg; die eerste keer met geweld van buite deur die mag van wapens, die ander twee keer deur die mag van die gees."

Van Rome se drie oorwinnings was die sege van sy reg vir ons die blywendste. Die geskiedenis van die eintlike Romeinse reg is in die sesde eeu n.C. afgesluit. Maar sedert die herontdekking daarvan in Italië gedurende die 11 de eeu-'n twee- tot driehonderd jaar na wat beskou kan word as die onstaan van Europa onder Karel die Grote-, in sy verering as ratio scripta gedurende die Middeleeue, en deur sy resepsie veral in Nederland en Duitsland in die $15 \mathrm{de}$ en $16 \mathrm{de}$ eeue, loop vir ons één ononderbroke lyn van Europese kultuurgeskiedenis van naastenby nege eeue. In Suid-Afrika geld ons reg vandag as die direkste, onmiskenbaarste band met daardie deel van die kultuur van Rome en Europa wat die 
grondslag van ons volkslewe uitmaak. Ook Suid-Afrika is ingesluit binne die sfeer van Rome se oorwinning oor Europa. Die Romeinse staat is vir ons vandag ' $n$ historiese verskynsel, die kerk van Rome is nie ons kerk nie-maar die reg van Rome is ons reg, lewende reg, meer as vir enige ander volk ter wêreld.

Tog is ons ook op die gebied van die reg nie suiwer navolgers van Rome nie. Die reg wat ons volksplanter na Suid-Afrika gebring het, is nie net Romeinse reg nie. Dit is Wes-Europese, Vastelandse reg. Dit is 'n samesmelting van Romeinse en Germaanse en Christelike reg. En dit heet Romeins-Hollands omdat dit meer bepaald 'n Nederlandse en veral Hollandse tak van die Europese jus commune is.

As Europese reg het dit al die invloede ondervind wat bygedra het tot die vorming van die Europese beskawing wat ons in Afrika verteenwoordig. Die Roomse kerk het 'n beskawende invloed daarop uitgeoefen deur middel van die Kanonieke reg, bv. in die afskaffing van onnodige formalisme van die Romeinse reg; so het die beginsel pacta sunt servanda die kontraktereg bevry van die bande van die Romeinse reg en terloops aangesluit by die oud-Germaanse idee wat ons nog ken in die spreuk ,'n man 'n man, 'n woord 'n woord." Die Renaissance het ook in die reg dit individu gehelp emansipeer, en op hierdie beginsel het die Hervorming uit die aard van die saak nadruk gelê en tog ook die bestaan van regmatige gesag erken.

Buitendien is die Romeins-Hollandse reg eintlik 'n Hollands-Romeinse reg. Materieel beskou, is dit minsteris twyfelagtig of die Romeinse reg die dominerende bestanddeel daarin is. Maar die Romeinse reg het wetenskaplik so 'n merkbare uitwerking op die beginsels van ons reg gehad, dat met reg daaraan die ereplek in die naam van ons stelsel toegeken word, hoeseer dit origens liewer as aanvullend by die Hollandse reg beskou moet word soos ontwikkel uit die Germaanse gewoontes en volksregte en onder invloed van die kerk.

Met opset benadruk ons in elk geval die plek van die Romeinse reg in ons regsisteem. Dit is per slot van rekening die Romeinse reg wat die grenslyn trek tussen die twee groot stelsels van reg wat die Weste ken: die Vastelandse reg, waarvan ons reg 'n tak is, en die Engelse „common iaw", wat in grondslag en reël so dikwels radikaal daarvan verskil. Die Engelse reg is in wese Germaanse reg. Dit het in wetenskap in 'n mate, in vorming en praktyk feitlik gladnie die invloed van Rome ondergaan nie.

Die 300-jarige fees wat ons vanjaar vier, is vir ons die fees van die koms van die Europese beskawing na suidelike Afrika. Dit moet 'n wekroep wees in hierdie belangrike fase van ons kultuurtaak in Afrika. Eers 
in die tweede plek mag die fees van Jan van Riebeeck die aandag vra vir 'n "Dietse verband", wat vandag nou eenmaal nie meer besonder na aan die hart van die volk van Suid-Afrika lê nie. Ook ons reg is amptelik en geldiglik Romeins-Hollandse reg, maar sy taak in hierdie land is veeleer dié van 'n draer van Europees-Christelike beskawing in Afrikaen dit alles tot meerdere eer van die volk en die persoon wat die weg ook vir ons reg na Suid-Afrika gebaan het.

As die suiwere handhawing van ons reg as kulturele erfenis ter sprake kom, dan is die eerste vraag dié na die verhouding van ons reg as Romeinsregtelik georiënteerde Wes-Europese reg tot die wesensverskillende Engelse reg. Nou is dit bekend dat die reg van die Afrikaner netsoos sy taal en kukltuur in die algemeen sedert anderhalf-eeu in stryd gewikkel was met die destydse veroweraar uit Brittanje. Ons algemene kultuur ht in hierdie proses-dit moet elke nugtere beoordelaar selfs teen wil en dank erken-minder Vastelands en grotendeels Engels geword, al is dit dan in 'n Suid-Afrikaanse vorm. En ons reg in besonder?

Vir die waarnemer uit Engeland en selfs vir die Suid-Afrikaanse leek moet dit dikwels na 'n mite klink as gewag gemaak word van die SuidAfrikaanse reg as"'n Romeins-Hollandse reg. Op hierdie feit het sir John Wessels reeds in 1907 in sy bekende werk oor die geskiedenis van die Romeins-Hollandse reg die aandag gevestig. Jy woon die verhoor van 'n geskil aangaande 'n kontrak in die hof by; jy herken in die pleitstukke bekende Engelse vorme, terme en begrippe; jy merk dat suiwer Engelsregtelike reëls van bewyslewering gevolg word, en jy staan dikwels verbaas dat selfs die regter sy uitspraak grond op Engelse outoriteite, miskien sonder verwysing na 'n enkele kenbron van ons eie gemenereg. Wat ons materiële reg betref, is so 'n verskynsel weliswaar vandag seldsamer as destyds, om redes wat ons hieronder sal aantoon. Wat die reëls aangaande bewyslewering en prosedure betref-laat ons dadelik die feit aanvaar dat hulle nou eenmaal in die dae van die Kaapkolonie deur die Britse owerheid verengels is, en miskien nie sonder geldige rede nie netsoos ons staatsreg veral met die aanvaarding van die parlementêrr stelsel vanselfsprekend hoofsaaklik 'n Engelsregtelike grondslag verkry het.

Maar ons privaatreg-daardie primêre deel van die reg wat vir die regsgenoot die naaste aan die hart lê omdat dit sy familielewe, sy kon trakte, sy erfenis, sy persoon direk raak-wat was die lotgevalle van ons privaatreg wat eintlik dié Romeins-Hollands reg is? En ons Romeins. Hollandse strafreg?

Ongetwyfeld het sterk invloede die behoud ook van hierdie verreweg vernaamste afdelings van ons gemenereg teengewerk. Aanvanklik, met 
die finale oorname van die Kaap cieur die Engelse, het die RomeinsHollandse reg hier bly geld kragtens die beginsel van die Engelse reg dat ' $n$ verowerde of gesedeerde gebied sy regstelsel behou. Die voortbestaan van die koloniste se ou reg is dan ook uitdruklik gewaarborg in die kapitulasievoorwaardes, eers in 1795 en weer in 1806. Daarmee is u ysiging van die reg volgens die gewone wetgewende prosedure natuurlik nie uitgesluit nie.

Behalwe wetgewing van die veroweraar het verskillende ander faktore egter bygedra tot die geleidelike invoering van Engelse reg in SuidAfrika na 1806 . Aandag verdien veral die faktore wat uit die aard van ons gemenereg self voortvloei.

Dit is bekend dat die Romeins-Hollandse reg 'n stelsel is wat op breë, billike begrinsels berus wat verder gekenmerk uord deur hul rekbaarheid en aanpassingsvermoë. Juis dáárom is dit so 'n voortreflike stelsel, en alleen dáárom kan dit vandag nog so uitmuntend voorsien in die behoeftes van ' $n$ moderne samelewing. Maar ook dáárom bied dit aan die regter die geleentheid om sy eie stempel op die reg af te druk. Buitendien staan ons reg nie in 'n wetboek opgeteken nie; dit is eintlik gewoonteregr wat nie deur vaste wetlike bepalings geknel word nie. Des te meer leen dit hom tot wysiging en aanpassing maar ook tot beïnvloeding deur ander stelsels.

Hierdie karaktertrek van ons reg moet beslis as goed en voordelig beskou word. En insoverre die Engelse reg as gevolg daarvan ingang in Suid-Afrika verkry het, is die resultaat oor die algemeen 'n verryking van ons reg. Die Engelse reg is 'n stelsel wat noodgedwonge tred moes hou met die lewe en behoeftes van 'n groot moderne volk en daarby 'n vooraanstaande handelsvolk. Dit het regsinstellings ontwikkel wat aan die ouer Romeins-Hollandse reg onbekend was. Dit het ook 'n ryke kasuïstiek gebied met gebruikmaking waarvan ons rekbare regsbeginsels aangepas kon word by die moderne tyd. 'n Uitmuntende voorbeeld vind mens op die gebied van die onregmatige daad. Dáár is ons reg, soos later sal blyk, weliswaar vertroebel en benadeel deur Engelse reg maar ook verryk. Ons stelsel ken ook hier sterk, algemene beginsels, gegrond op die Romeinse reg. Maar in die hedendaagse lewe bestaan allerlei vorms van onregmatige daad wat aan die ouer volke nie bekend was nie. 'n Voorbeeld is onbehoorlike mededinging in die handel. Ons reg bied die grondslag vir die erkenning en bekamping van hierdie onregmatige daad, maar die wyse waarop dit in die praktyk moet geskied, word deur die reg van 'n groot moderne en industriële land ten beste aangedui. Hier het ons reg dan ook met vrug geleen by die Engelse reg. 
Miskien spreek die verryking van ons reg deur die Engelse reg die duidelikste op die gebied van die handelsreg. Dit is uit die aard van die saak 'n betreklik moderne afdeling van die reg, wat veral deur die Engelse as 'n toonaangewende handelsvolk sterk uitgebou is. Hier was die ou Romeins-Hollandse reg weer heeltemal ontoereikend. Selfs die gewone beginsels van ons kontraktereg is dikwels met goeie gevolg deur die Engelse handelsreg beïnvloed. Maar in besonder is ons wetgewing in verband met die handelsverkeer grotendeels gebou op Engelsregtelike grondslag; sprekende voorbeelde is die Insolvensiewet, die Wisselwet, die Maatskappyewet en versekeringswetgewing-om maar 'n paar te noem.

Die suiwer Afrikaans-nasionaal-voelende persoon mag 'n ontwikkeling soos hierdie betreur; dat ons reg daardeur wesenlik benadeel is, kan hy beswaarlik beweer. Met reg sou hy kan eis dat ons meer hulp gaan soek by 'n verwante stelsel, soos die Duitse of die Nederlandse, maar die Engelse reg is nou eenmaal deur die historiese ontwikkeling in nouer praktiese kontak met ons land gebring, en sy bydrae mag daarom nie misken word nie.

Minder gelukkig, selfs gevaarlik en nadelig, was die invloed van die Engelse reg as gevolg van ' $n$ ander omstandigheid in verband met ons reg. Dit is die aard van ons regsbronne wat in die verlede ' $n$ groot mate van onbekendheid met ons gemenereg in die hand gewerk het. Dit klink byna fantasties dat 'n regter of 'n advokaat van die Hooggeregshof met die reg wat sy hof geroepe is om toe te pas, nie behoorlik bekend kan wees nie. En tog was dit in die verlede in ons land dikwels die geval.

Uitstekend soos die Romeins-Hollandse regstelsel ongetwyfeld is, moet toegegee word dat dit allermins 'n reg is waarvan die beginsels maklik outoritatief vasgestel kan word. Allereers bestaan daar tot vandag toe nog 'n mate van twyfel oor presies watter reg van die provinsie Holland in Suid-Afrika van toepassing geword het. Immers, naas die jus commune was daar ook nog die keure en kostume en al die plakkate. Maar selfs die gewone gemenereg kan slegs behoorlik bestudeer word aan die hand van 'n groot aantal werke van die Nederlandse juriste veral van die $17 \mathrm{de}$ en 18de eeue. Vanaf die $16 \mathrm{de}$ tot die 19de eeue het benewens baie ander 'n 70-tal juriste van formaat oor die Romeins-Hollandse reg geskryf. Hul werke is geskryf in Latyn of in ou Nederlands. Origens is die Romeinse reg soos saamgevat in die Corpus Juris Civilis van keiser Justinianus self nog 'n belangrike bron van ons reg-en om dit te kan gebruik moet mens weer presies vasstel hoeveel daarvan in Holland geresipieer is. Buitengewone eise word dus gestel aan die opleiding van 'n Suid-Afrikaanse juris. 
Voeg daarby dat daar in Suid-Afrika eers sedert ongeveer 30 jaaı regsfakulteite bestaan wat die opleiding van juriste behoorlik kan waarneem. Is dit dan enigsins merkwaardig as regters en advokate van die verlede, te meer as hulle meesal hul opleiding in Engeland ontvang het, dikwels teruggedeins het voor die gedugte taak om die beginsels van ons reg op te diep wanneer hulle die meer bekende Engelse reg byderhand gehad het, miskien ook in 'n bonte mengeling van bronne, maar dan minstens in moderne handboeke uiteengesit?

Hier het ons reg inderdaad voor die groot toets te staan gekom. Sy lewe moet dikwels in gevaar gewees het teenoor sy sterk mededinger. In die praktyk van ons reg oor die afgelope 100 jaar het dit maar alte dikwels gebeur dat Engelsregtelike beginsels wat in ons regsisteem nie tuishoort nie, goedsmoeds as deel van die Romeins-Hollandse reg toegepas is. Gelukkig het ons regspraktyk ook sedert 'n 60 jaar 'n hele aantal regters van formaat opgelewer wat op deeglik wetenskaplike grondslag die gety geleidelik laat kenter het. Menige valse leerstelling is weer uitgewerp en deur egte Romeins-Hollandse reg vervang. Bekend is hier byvoorbeeld die uiteindelike verwerping ná langdurige regterlike stryd van die vir ons reg valse leer van die common law dat 'n kontrak slegs geldig is indien daar aan albei kante 'n prestasie beding is. Lank is reeds weer in ere herstel die gesonde beginsel van die Romeins-Hollandse reg dat die ernstiglik gegewe woord as sodanig bindend is; ook 'n skenking is dus ' $n$ geldige kontrak.

Die stryd om die handhawing van die Romeins-Hollandse reg as volksbesit en om sy wetenskaplike suiwerheid het danksy 'n paar groot figure op die regbank goeie vrugte afgewerp. Die amptelike verslae van ons hofuitsprake bevat reeds 'n massa suiwer geformuleerde gemenereg. Dat intussen alle nadelige beïnvloeding uitgeskakel is, wil mens nie beweer nie. Die spore van vreemde en met ons volk se regsoortuiging strydige beginsels en leerstellings is soms nog duidelik waarneembaar. Om enkele voorbeelde te noem. Vir die gewone Afrikaanse regsgenoot is dit verkeerd en onbillik dat iemand op grond van laster vir die betaling van 'n aansienlike bedrag aanspreeklik gehou kan word sonder dat die eiser selfs hoef te bewys dat die beweerde lasterlike woorde met kwaaie bedoeling uitgespreek is. Goeie Romeins-Hollandse reg vereis hier 'n bedoeling om te benadeel, kwaadwilligheid, aan die kant van die verweerder; ons howe het verkies om die Engelse reg na te volg en die vereiste van kwaadwilligheid op die agtergrond te skuif.

Eweseer het ons praktyk 'n dwaalspoor uit die Engelse reg gaan volg toe dit die reêls van die Engelsregtelike beginsel van ,bydraende nalatigheid" begin toepas het. Die gevolg is dat die eiser wat deur onregmatige 
daad skade gely het weens die heeltmal oorwegende skuld van die verweerder, dikwels nie 'n pennie kan verhaal indien die verweerder maar bewys dat daar by die eiser self óók selfs 'n geringe mate van skuld aanwesig was nie. So onbillik werk hierdie leer dat die wetgewer tans die afskaffing daarvan oorweeg-en dit val te betreur as die wetgewer eers ingeroep moet word om gesonde volksreg te herstel.

Ook ons strafreg wemel byna van verkeerde invloede uit die Engelse reg, wat op hierdie gebied soms beslis 'n agterlike indruk maak. Skokkend is byvoorbeeld die leerstuk wat ons howe uit die Engelse reg ingevoer het, $\mathrm{nl}$. dat 'n misdaad kan bestaan vir die pleeg waarvan 'n skuldige gesindheid by die dader nie 'n vereiste is nie. Hierdie leerstuk van die sgn. absolute verbod druis in teen alle moderne strafregsopvattings en kan deur ons howe vermy gewees het as hulle reg laat geskied het aan die ryke skuldbegrip van ons gemenereg, wat immers nalatigheid naas opset as skuldvorm ken. En wat moet 'n mens dink van nog 'n Engelsregtelike dogma, nl. dat 'n persoon in sekere omstandighede verantwoordelik gehou kan word vir die misdaad deur 'n ander gepleeg? Klink dit na die stem van die Justitia van Nürnberg?

Hoe staan dit met ons reg vandag? Met verderflike uitsonderings soos die genoemdes kan niemand ernstiglik beweer dat die beginsels van ons gemenereg erg teruggedring of benadeel is onder invloed van Engelse reg nie. Buitendien is 'n skool van wetenskaplik gevormde Suid-Afrikaanse regters en ander juriste sedert 'n aantal jare doelbewus daarop ingestel om die grondbeginsels van ons gemenereg suiwer uit te werk en te handhaaf. 'n Belangrike bydrae word gelewer deur ons regsfakulteite, waaronder die twee groot Afrikaanse fakulteite 'n vooraanstaande plek inneem, nie alleen in die stryd om die handhawing van suiwer Romeins-Hollandse reg nie maar ook in die navorsing en beskrywing daarvan.

Oor die algemeen sal selfs die vurige Afrikaner-nasionalis moet toegee, soos een van die vaders van die Afrikaanse regswetenskap, wyle prof. Bodenstein, selfs in 1912 aangedui het, dat die invloed van die Engelse reg in ons land nie betreur hoef te word nie. Voorwaarde bly natuurlik altyd: dat vreemde reg nie ingevoer word om beginsels van ons eie reg te verdring nie. Dáár waar die beginsels van Engelse reg en Romeins-Hollandse reg dieselfde is, kan met vrug geput word uit die ervaring van die Engelse regspraktyk soos opgeteken in die ryke bron van Engelse hofverslae; en waar ons reg in sommige rigtings in moderne omstandighede tekort mag skiet, het die Engelse reg reeds baie nuttige aanvullingswerk gedoen. 
Ons eie gemenereg het in Suid-Afrika sy voortreflikheid en sy lewenskrag teenoor sy magtige konkurrent uit Engeland finaal bewys. Sy beginsels leef in die hart en in die regsoortuiging van ons volk-indien nog nie in 'n samevattende wetboek wat elke Suid-Afrikaner kan besit en lees en verstaan nie. Hierin is miskien ' $n$ tekortkoming van ons reg geleë. Dit is 'n volksreg, maar 'n volksreg moet in breë beginsels in hanteerbare vorm vir die volk beskikbaar wees. Moontlik is die dag nie meer veraf wanneer in alle erns gedink sal word aan die kodifikasie van ons gemenereg nie. So 'n stap sal alleen die vrug mag wees van jarelange wetenskaplike en praktiese bearbeiding van die ou bronne van ons reg, want 'n kode moet werklik die beginsels van ons gemenereg verteenwoordig. Tot daardie dag aanbreek, sal die sug nog menigmaal gehoor word wat opstyg uit die volk van Transvaal in sy memorie aan die Volksraad in 1872-of is dit die klag van die Afrikaanse regstudent worstelende met Latynse regstekste?-,inhoudende verzoek die groote zee van Hollandsche wetboeken, waaronder het geheele land verzopen is, te vernietigen"!

„Het onze moeten wij niet verwerpen . . ." Na 300 jaar leef nog in ons land in volle $\mathrm{krag}$ die grondslae van die reg van Rome, van WesEuropa en van Jan van Riebeeck, die reg wat ons tasbare band met nege ceue Europese kultuur vorm. Ons reg het hom gehandhaaf teen 'n magtige mededinger. Uit sy aanvaarding van bruikbare bydraes uit die vreemde reg spreek sy $\mathrm{krag}$ eerder as sy swakheid. Spreek daaruit ook die feit dat ons volk en ons kultuur nou eenmaal nie geroepe was om naastenby Diets- of selfs suiwer Vastelands-Afrikaans te bly nie? 